\title{
Performance of UK National Health Service compared with other high income countries: observational study
}

Check for updates

\author{
Irene Papanicolas, ${ }^{1,2,3}$ Elias Mossialos, ${ }^{1}$ Anders Gundersen, ${ }^{3}$ Liana Woskie, ${ }^{1,2,3}$ Ashish K Jha ${ }^{2,3}$
}

${ }^{1}$ Department of Health Policy, London School of Economics and Political Science, London, UK

${ }^{2}$ Department of Health Policy and Management, Harvard TH Chan School of Public Health, Boston, MA, USA

${ }^{3}$ Harvard Global Health Institute, Cambridge, MA, USA

Correspondence to:

I Papanicolas

I.N.Papanicolas@lse.ac.uk

(ORCID 0000-0002-8000-3185)

Additional material is published online only. To view please visit the journal online.

Cite this as: BMJ 2019;367:16326 http://dx.doi.org/10.1136/bmj.l6326

Accepted: 25 October 2019

\section{ABSTRACT}

OBJECTIVE

To determine how the UK National Health Service (NHS) is performing relative to health systems of other high income countries, given that it is facing sustained financial pressure, increasing levels of demand, and cuts to social care.

DESIGN

Observational study using secondary data from key international organisations such as Eurostat and the Organization for Economic Cooperation and Development.

SETTING

Healthcare systems of the UK and nine high income comparator countries: Australia, Canada, Denmark, France, Germany, the Netherlands, Sweden, Switzerland, and the US.

\section{MAIN OUTCOME MEASURES}

79 indicators across seven domains: population and healthcare coverage, healthcare and social spending, structural capacity, utilisation, access to care, quality of care, and population health.

RESULTS

The UK spent the least per capita on healthcare in 2017 compared with all other countries studied (UK $\$ 3825$ (£2972; €3392); mean \$5700), and spending was growing at slightly lower levels $(0.02 \%$ of gross domestic product in the previous four years, compared with a mean of $0.07 \%$ ). The UK had the lowest rates of unmet need and among the lowest numbers of doctors and nurses per capita, despite having average levels of utilisation (number of hospital admissions). The UK had slightly below average life expectancy ( 81.3 years compared with a mean of 81.7) and cancer survival, including breast, cervical, colon, and rectal cancer.

\section{WHAT IS ALREADY KNOWN ON THIS TOPIC}

The UK National Health Service (NHS) has faced sustained financial pressures while handling increasing demand

Cuts to social care have coincided with an increase in the population of older people

The NHS has increased productivity and efficiency in recent years, but it still faces substantial challenges

\section{WHAT THIS STUDY ADDS}

The UK spent the least per capita on healthcare in 2017 compared with nine high income comparator countries, and spending was growing at slightly lower levels Factors contributing to the relatively low expenditure in the UK include lower levels of staffing, lower rates of utilisation, and less provision of long term care than comparators

The NHS showed pockets of good performance, including in health service outcomes, but spending, patient safety, and population health were all below average to average at best
Although several health service outcomes were poor, such as postoperative sepsis after abdominal surgery (UK 2454 per 100000 discharges; mean 2058 per 100000 discharges), 30 day mortality for acute myocardial infarction (UK $7.1 \%$; mean $5.5 \%$ ), and ischaemic stroke (UK 9.6\%; mean 6.6\%), the UK achieved lower than average rates of postoperative deep venous thrombosis after joint surgery and fewer healthcare associated infections.

\section{CONCLUSIONS}

The NHS showed pockets of good performance, including in health service outcomes, but spending, patient safety, and population health were all below average to average at best. Taken together, these results suggest that if the NHS wants to achieve comparable health outcomes at a time of growing demographic pressure, it may need to spend more to increase the supply of labour and long term care and reduce the declining trend in social spending to match levels of comparator countries.

\section{Introduction}

The UK's spending on healthcare has been constrained for some time, with slow growth in spending in a setting of steadily increasing demand as the population ages and other safety nets for the older population are cut. ${ }^{1}$ From 2010 to 2017, the number of people aged over 80 rose by 340000 . In the same period, real public spending on social care fell by $1 \%$ and spending on adult social care fell by $6.4 \%{ }^{2}$ As a result of the great fiscal pressure facing the National Health Service (NHS), there has been an increased effort to improve the efficiency of the health system by various means including, but not limited to, reductions in reimbursement rates, staff freezes, and cuts to administrative and prescribing costs. ${ }^{3}{ }^{4}$ Since 2009 productivity in the NHS has risen faster than in other sectors of the British economy, but recent strikes have brought matters such as staffing gaps, inadequate pay, and patient safety to global attention. ${ }^{5}$

The UK NHS is not the only health system facing the challenge of having to meet growing demand from patients while under pressure to reduce healthcare costs. ${ }^{6}$ However, few studies have looked abroad to understand whether other healthcare systems can provide lessons for the NHS. ${ }^{4}$ Where comparisons exist, they often focus on specific aspects of the system, such as spending, cancer care, or quality, and show a mixed picture of relative performance. Fortunately, new national data have become available over the past few years that allow for a careful comparison not just of spending but also of broader health system performance including access, quality, and outcomes. Comparative data on how the UK performs relative to 
other high income countries across a set of important metrics would be helpful but have been lacking.

Therefore, in this study, using comparable data from several international organisations including the Organization for Economic Cooperation and Development (OECD), we sought to compare the UK health system with those of nine other countries across seven main domains: population and healthcare coverage, health and long term care spending, structural capacity, utilisation, access, quality, and population health. Our hypothesis was that if austerity has harmed the NHS, we would see this in higher population and patient dissatisfaction, drops in access and utilisation, and worsening quality and population health status. If, however, we continue to see comparable performance and trends of performance in line with other countries also trying to meet changes in sociodemographics, this probably suggests a health system that has been able to cut waste and operate more efficiently than other high spenders. Unfortunately, comparative detailed data on the performance of the NHS across the four constituent countries of the UK (England, Scotland, Northern Ireland, and Wales), where the NHS is structured differently, are not available. Therefore, we examined UK performance as a whole. Given the greater population size of England, the performance metrics we report will be dominated by the performance of the English NHS.

\section{Methods}

\section{Selection of study and comparator countries}

We examined the UK and nine comparator high income countries. Data for the UK represent the NHS and not the privately financed healthcare sector. Moreover, although the NHS is structured differently across the four countries of the UK, particularly when it comes to the provision of social care (often referred to as long term care), in this paper we consider the performance of all these systems together. Given the greater population size of England, the UK performance metrics reported in this study are dominated by the performance of the English NHS.

We chose the comparator countries because they are all high income countries, are members of the G12, and have populations with similar demographic characteristics that face similar burdens of illness, but also have healthcare systems that are structured in different ways. ${ }^{8}$ On the basis of these criteria, we compared the UK with the US, Canada, Germany, Australia, Sweden, France, Denmark, the Netherlands, and Switzerland. The comparator countries represent different geographical areas and diverse health system structures. In addition, we compared all performance metrics with the OECD average and the EU average to allow for a broader comparison.

\section{Data sources}

Data came from a range of databases compiled by international organisations, with most coming from the OECD. Data on spending, structural capacity, workforce, utilisation, access, and quality came from
OECD.stat and the OECD Health at a Glance reports. Additional data came from the World Bank, the Institute for Health Metrics Evaluation, and Eurostat. We gathered perceptions of health systems, staff satisfaction, unmet need, time spent with general practitioner, patient-general practitioner experiences, care continuity, and waiting time indicators from various Commonwealth Fund international surveys, including the Surveys of Primary Care Physicians, the Health Policy Surveys of Older Adults, and the International Health Policy Surveys.

We translated all data on remuneration into US dollar equivalents, with exchange rates based on 2016 purchasing power parities of national currencies. ${ }^{9}$ When data were not available for a given country, or more accurate country level estimates were available, we used country specific data sources. For example, to highlight the differences in total healthcare expenditure in the UK between the OECD's System of Health Accounts (SHA) classification of healthcare spending and the previous accounting methods used, we used health spending data from the Office for National Statistics. Detailed descriptions of all variables and what they capture is included in the supplementary technical appendix.

\section{Selection of variables}

To better understand the UK's healthcare performance relative to other high income countries, we reviewed a range of variables. We first examined comparative data on the size and make-up of the populations of the different countries and their rates of healthcare coverage. We then compared spending on health and long term care, including the proportion of spending coming from public and private sources. As countries organise their benefit packages for health and long term care differently, with some countries drawing different boundaries between what is and is not funded from the healthcare budget, we used data from the OECD's SHA classification as a basis for comparison. This includes all spending on health related components of long term care, regardless of which national budget they are included in or whether they are public, private, or out of pocket.

Next, we examined comparative inputs, including workforce and structural capacity such as hospital beds, which aside from contributing to direct costs may also influence maintenance costs or the cost of using equipment. Given current debates in the UK about migration, we also included descriptive statistics on the percentage of migrants represented in the healthcare workforce and in the general population. In recent years, policy makers in the UK have advocated for more efficiency gains in the healthcare system or, in other terms, the transformation of existing healthcare expenditures into the same amount of, or more, health system outcomes. We therefore extended our analysis to examine a range of intermediate outputsnamely, access and utilisation, patients' and general practitioners' experience, and quality of care-as well as indicators of population health status, such as life 
expectancy and mortality amenable to healthcare to examine the change in performance of these areas over a period of reduced growth in healthcare spending. We standardised all data on structural capacity and/or utilisation to the population or patient, and all health service outcome data were adjusted for age and sex by the OECD. Details on all indicators can be found in the technical appendix.

To provide a broader context of overall factors that can contribute to differences in healthcare spending and consider the UK debate about recent austerity measures and their effect on NHS demand, we also examined social spending more broadly (that is, spending on social programmes, specifically on unemployment, family, old age, incapacity, survivors, housing, and active labour market programmes), as well as demographic differences, risk factors, and prevalence of disease. In line with previous international comparisons, the healthcare system included all groups of which the primary intent is to improve health. ${ }^{10}$

This approach resulted in the presentation of a total of 79 indicators across seven domains: population and healthcare coverage, health and long term care spending, structural capacity, access to care, utilisation, quality of care, and population health. In each domain, we selected measures that were available across most of the countries in the analysis. In the area of quality, the focus was on indicators that captured quality of prevention, primary care, and inpatient care, across the areas of appropriateness, effectiveness, experience, and safety. In the area of access, we explored variations related to waiting times and unmet need for healthcare.

The focus of our analysis was on indicators from 2017, as well as the trends in data from 2010 when available and comparable. If data from either 2017 or 2010 were not available, we used the nearest available year (for example, data from 2016 instead of 2017). We note aspects of comparability and timeliness for each indicator in the technical appendix. In each table, we present the average of each indicator across all 10 countries including the UK, along with the averages of OECD and European Union member countries.

\section{Patient and public involvement}

There was no patient or public involvement in this research.

\section{Results}

\section{Population and healthcare coverage}

The make-up of the UK population, in terms of size of total population and the percentage of the population over 65 years of age was similar to the study average (population in UK, 66.4 million; study average, 64.7 million; population over 65 in the UK, $18 \%$; study average, 19\%) (table 1). Rates of growth for these metrics in the UK were similar to the study average as well. The proportion of the population over 65 in the UK was slightly greater than the mean of the OECD member nations (17\%), but equal to the mean of EU member nations (18\%). The UK reported among the lowest rate of adults with multiple chronic conditions (UK, 14\%; study average, 18\%). The percentage of the total population born outside of the country was slightly lower in the UK than in our comparator countries in 2017 (UK, 14.2\%; study average, 17.1\%), although it was quite close to the average OECD and EU member state (OECD average, 13.8\%; EU average, $13.2 \%)$. However, the increase in the foreign born population from 2010 was above the average among comparators (UK, 2.9\%; study average, 1.8\%), and much higher than both the OECD average (0.7\%) and the EU average $(0.9 \%)$, particularly among the population coming from the EU. Among comparator countries, the UK had among the highest proportions of the foreign born population coming from the EU, after Switzerland, although this was in line with the averages of all OECD and EU member states.

All countries with the exception of the US were similar in terms of having nearly $100 \%$ of the population with healthcare coverage (table 1). Rates of private health insurance coverage varied widely across countries. This is largely explained by the different function of private insurance coverage across the countries. For example, private insurance in the UK largely reflects duplicative private insurance policies that allow people to access private healthcare in addition to the NHS. In Germany, the private insurance is mostly substitutive and reflects contributions from people who have opted out of the statutory health insurance system and whose main form of coverage is the private healthcare system. In France, health insurance reflects complementary addon policies that allow individual reductions in co-pays or increased accessibility to particular drugs, services, or both. However, private insurance coverage in the UK was below the average of the comparator countries, as well as the OECD and EU member state average (UK, $10 \%$; study average, $52 \%$; OECD average, $35 \%$; EU average, $32 \%$ ) and had declined over the previous decade (UK, $-1 \%$; study average, $1 \%$; OECD average, $2 \%$; EU average, $3 \%$ ). These numbers do not reflect the range of services covered or the depth of coverage.

\section{Healthcare and social spending}

The UK had the lowest healthcare expenditure per capita relative to our comparator countries (UK, \$3825 (£2972; €3392); study average, \$5700), although this was roughly in line with the average healthcare expenditure of the OECD member states (\$3854) and the EU member states (\$3616) (table 2). The OECD reports per capita spending for the UK to be $\$ 3943$, which also reflects components of social care that are included in expenditures for other countries (supplementary figure A). Expressed as a proportion of gross domestic product (GDP), the picture was similar, with the UK spending approximately $8.7 \%$ of GDP compared with the study average of $11.5 \%$ of GDP in 2017 (fig 1). Even if long term care (referred to as social care) expenditures are included in healthcare spending to allow for a more similar comparison across countries, UK expenditure remains below the comparator average ( $9.8 \%$ of GDP) 


\begin{tabular}{|c|c|c|c|c|c|c|c|c|c|c|c|c|c|}
\hline & Study average & OECD average & EU average & UK & AUS & CAN & FRA & GER & NLD & SWE & $\mathrm{CHE}$ & US & DEN \\
\hline \multicolumn{14}{|l|}{ Population } \\
\hline Total population, millions & 64.7 & 36.2 & 18.3 & 66.4 & 24.9 & 37.1 & 66.9 & 82.9 & 17.2 & 10.2 & 8.5 & 327.2 & 5.8 \\
\hline Change & 3.3 & 1.6 & 0.4 & 3.7 & 2.9 & 3.1 & 2.2 & 1.1 & 0.6 & 0.80 & 0.7 & 17.8 & 0.3 \\
\hline Population over $65, \%$ & 19 & 17 & 18 & 18 & 16 & 17 & 20 & 21 & 19 & 20 & 18 & 16 & 19 \\
\hline Change & 2 & 2 & 2 & 2 & 2 & 3 & 3 & 1 & 4 & 2 & 1 & 3 & 3 \\
\hline Adults with multiple chronic conditions, \% & 18 & NA & NA & 14 & 15 & 22 & 18 & 17 & 14 & 18 & 15 & 28 & - \\
\hline Foreign born, \% & 17.1 & 13.8 & 13.2 & 14.2 & 27.9 & 19.7 & 11.9 & 15.4 & 12.5 & 17.7 & 29.3 & 13.5 & 11.1 \\
\hline Change & 1.8 & 0.7 & 0.9 & 2.9 & 1.9 & & 0.7 & 2.5 & 1.4 & 3.5 & 3.1 & 1.0 & 3.7 \\
\hline Foreign born from EU, \% & 30.1 & 34.4 & 33.8 & 34.6 & 31.9 & 26.0 & 26.7 & 32.7 & 25.1 & 28.4 & 56.2 & 7.3 & 31.7 \\
\hline Change & -0.4 & 2.6 & 0.9 & 3.1 & -6.2 & -1.1 & -1.4 & 1.7 & 3.0 & -5.9 & 2.0 & -1.4 & 2.4 \\
\hline \multicolumn{14}{|l|}{ Health insurance } \\
\hline $\begin{array}{l}\text { Population covered by government/social } \\
\text { health insurance, } \%\end{array}$ & 93 & 93 & 98 & 100 & 100 & 100 & 99.9 & 89.4 & 99.9 & 100 & 100 & 36 & 100 \\
\hline Change & 1 & -2 & 1 & 0 & 0 & 0 & 0 & 0.4 & 0.3 & 0 & 0 & 5 & 0 \\
\hline $\begin{array}{l}\text { Population covered by private health } \\
\text { insurance, \% }\end{array}$ & 52 & 35 & 32 & 10 & 54 & 67 & 96 & 34 & 84 & NA & 29 & 63 & 29 \\
\hline Change & 1 & 2 & 3 & -1 & 2 & -1 & -0.3 & 3 & -5 & - & 0.6 & 2 & 8 \\
\hline
\end{tabular}

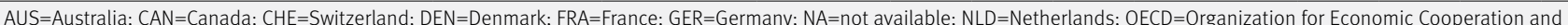

Development; SWE=Sweden

Values are 2017 or nearest year. Change represents difference from 2010 (or nearest year) values.

(supplementary figure A). As illustrated in figure 1 (and supplementary figure A), the rate of growth in total healthcare expenditure in the UK has fluctuated across the past two decades. Despite always spending a lower proportion of GDP than the average of the comparator countries, before 2009 healthcare expenditure in the UK grew faster than the average of the other nine countries. This was particularly pronounced during the period of 2000-09, reflecting the commitment of the Blair government to match UK NHS spending to the European average. ${ }^{11} 12$ From 2009 onwards, the growth in UK healthcare expenditure slowed to its lowest levels whereas health expenditure growth in the comparator countries was notably higher, averaging a rate of $0.08 \%$ of GDP per year over the period 2011-14 compared with an average annual decrease of $0.03 \%$ of GDP in the UK, and a rate of $0.07 \%$ of GDP over the period 2014-17 in comparator countries compared with a rate of $0.02 \%$ of GDP in the UK.
The proportion of healthcare expenditures in the UK coming from public sources (general taxation and national insurance contributions, referred to as government/compulsory spending by the OECD) is close to the average of the comparator countries (UK, $79 \%$; study average, $80 \%$ ), but slightly higher than the averages of OECD and EU member states (OECD, 74\%; $\mathrm{EU}, 75 \%)$. In recent years in the UK, this spending has declined and been replaced by funding from private sources (-4\% over the period 2010-17). The average trend across the comparator countries has been the reverse, with a shift away from private funds to public funds shown by a mean of $4 \%$. This is higher than the increase across the OECD (an increase of $1 \%$ ) and the EU member states (a decrease of 1\%).

Total per capita spending on long term care in the UK was below the study average, but slightly above the average long term care expenditure across the OECD and EU. Social spending in the UK as a percentage of

\begin{tabular}{|c|c|c|c|c|c|c|c|c|c|c|c|c|c|}
\hline & Study average & OECD average & EU average & UK & AUS & CAN & FRA & GER & NLD & SWE & CHE & US & DEN \\
\hline \multicolumn{14}{|l|}{ Healthcare spending } \\
\hline $\begin{array}{l}\text { Per capita healthcare spending, 1000s } \\
\text { US } \$\end{array}$ & 5700 & 3854 & 3616 & 3825 & 4791 & 4812 & 4931 & 5848 & 5155 & 5264 & 7147 & 10207 & 5025 \\
\hline Change & 1222 & 775 & 629 & 583 & 1195 & 645 & 883 & 1436 & 682 & 1818 & 1851 & 2267 & 864 \\
\hline $\begin{array}{l}\text { Government/compulsory expenditure, \% } \\
\text { of total health expenditure }\end{array}$ & 80 & 74 & 75 & 79 & 69 & 70 & 83 & 84 & 82 & 84 & 64 & $85^{*}$ & 84 \\
\hline Change & 4 & 1 & -1 & -4 & 0.3 & -0.4 & 7 & 1 & -2 & 2 & 2 & $36^{\star}$ & 0.1 \\
\hline $\begin{array}{l}\text { Voluntary/out-of-pocket expenditure, \% } \\
\text { of total health expenditure }\end{array}$ & 20 & 26 & 25 & 21 & 31 & 30 & 17 & 16 & 18 & 16 & 36 & $15^{*}$ & 16 \\
\hline Change & -4 & -1 & 1 & 4 & -0.3 & 0.4 & -7 & -1 & 2 & -2 & -2 & $-36^{*}$ & -0.1 \\
\hline $\begin{array}{l}\text { Total long term care expenditure, per } \\
\text { capita, current US\$ }\end{array}$ & 930 & 633 & 573 & 738 & 100 & 734 & 750 & 1070 & 1366 & 1392 & 1381 & 511 & 1257 \\
\hline Change & 184 & 150 & 106 & 69 & 57 & 60 & 168 & 411 & 274 & 213 & 357 & 56 & 238 \\
\hline \multicolumn{14}{|l|}{ Social spending } \\
\hline Total social spending, \% GDP & 20.1 & 16.9 & 18.8 & 19.6 & 16.8 & 13.5 & 25.1 & 19.1 & 22.0 & 23.6 & 19.0 & 16.1 & 26.5 \\
\hline Change & 0.3 & -0.1 & -0.4 & -1.7 & 2.7 & -0.2 & 0.7 & -0.9 & 0.6 & 0.7 & 0.9 & -0.1 & 0.2 \\
\hline Public social spending, \% GDP & 15.7 & 14.8 & 17.2 & 13.9 & 12.2 & 10.3 & 23.2 & 16.8 & 15.0 & 20.1 & 12.9 & 10.4 & 22.3 \\
\hline Change & 0 & -0.2 & -0.4 & -1.5 & 1.4 & 0.1 & 0.7 & -1.1 & 0.4 & 0.1 & 0.5 & -0.9 & 0.3 \\
\hline
\end{tabular}

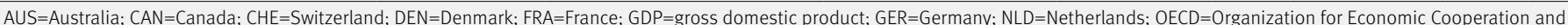
Development; $\mathrm{SWE}=$ Sweden

Values are 2017 or nearest year. Change represents difference from 2010 (or nearest year) values.

*In 2014 in US, employer provided health insurance was reclassified as compulsory expenditure whereas it had previously been classified as voluntary expenditure. 


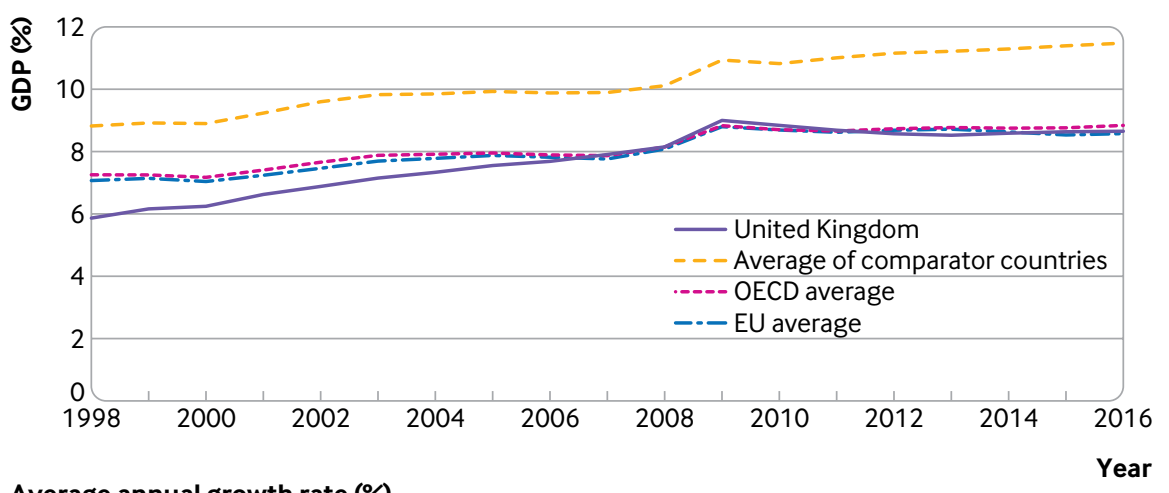

Average annual growth rate (\%)

Average of comparator countries

$0.22-0.09$

United Kingdom

0.23

0.23

0.07
0.20

$\begin{array}{ll}0.23 & 0.08 \\ 0.17 & -0.03\end{array}$

0.02

Fig 1 | Total expenditure on health in UK, comparator countries, Organization for Economic Cooperation and Development (OECD) member nations, and European Union (EU) member nations. Values for average annual growth rates are for indicated 4 year periods and are shown only for UK and average of comparator countries. Values for UK came from Office for National Statistics because they are consistent with years before implementation of System of Health Accounts (SHA) in 2011. More detailed information on SHA and differences between two accounting methods can be found in online technical appendix. An alternative to this figure, which has OECD reported values under SHA classifications for UK, is also available in supplementary figure $A$. GDP=gross domestic product

GDP was $19.6 \%$, which was similar to the study average of $20.1 \%$ but above the OECD average (16.9\%) and the EU average (18.8\%). However, UK social spending had been declining at a faster rate than all three groups over the previous five years. In addition, the relative proportion of public social spending decreased, whereas the proportion of public social spending in comparator countries remained relatively constant.

\section{Structural capacity}

The number of practising physicians in the UK was below the study average in 2017 (UK, 2.8; study average, 3.5 doctors/1000 population), and also lower than both the OECD and EU averages (OECD, 3.4; EU, 3.5 doctors/1000 population) (table 3). Although the UK had a comparable number of medical graduates to the average of the comparators (UK, 12.9; study average 12.5 graduates/100000 population) it also had the greatest decrease in graduates from 2010 to 2017 (UK, -0.7; study average, 1.7 graduates/100 000 population). Across the OECD and the EU, the numbers of medical graduates were slightly higher and had been increasing over the previous decade. The number of practising nurses in the UK in 2017 was considerably lower than all comparator countries and below the OECD and EU averages (UK, 7.8; study average, 11.4; OECD, 9.3; EU, 8.5 nurses/1000 population). We chose practising nurses rather than professionally active nurses owing to availability of data. Additionally, the UK was the only country to experience a decrease in the number of nurses from 2010 to 2017 (UK, -0.6; study average, 0.4; OECD, 0.9; EU, 0.5 nurses/1000 population). The numbers of nursing graduates in the UK were nearly half the number of nursing graduates in comparator countries (UK 29.4; study average
$56 / 100000$ population) and lower than the OECD (44.3/100000 population) and EU (37.4/100000 population) averages. The numbers of general practitioners and specialists in the UK were similar to those in all other countries.

The proportion of foreign trained doctors as a percentage of total doctors in the UK in 2017 was greater than the mean of comparators and higher than the OECD and EU average (UK, 28.6\%; study average, 21.4\%; OECD, 18.2\%; EU, 12.4\%) (table 3). This was also true for nurses, with foreign trained nurses representing $15 \%$ of the workforce in the UK in 2017 (study average, 9.3\%; OECD, 6\%; EU, 3.2\%). Recent figures on migration of health professionals for the UK show that the annual inflow of EU doctors and nurses has fallen since 2015. The annual inflow of doctors from the EU decreased from a high of 3326 in 2014 to 2064 in 2017, but these numbers were more than compensated for by an inflow of doctors from outside the EU (fig 2, bottom). The total annual inflow of nurses sharply decreased by $62 \%$ from 9168 in 2016 to 3462 in 2017 (fig 2, top). Whereas the annual inflow of nurses from outside the EU increased from 931 in 2016 to 2648 in 2017, the annual inflow of nurses from the EU decreased from 8237 in 2016 to 814 in 2017 (fig 2, top). Additionally, the stock of foreign trained nurses has declined; more than 3000 EU nurses left the NHS in 2017 (supplementary figure $\mathrm{B}$, right). Although numbers of nurses from outside the EU are increasing, this is not at a rate that compensates for the significant decreases in nurses coming from EU member nations.

The UK had the lowest percentage of physicians who were dissatisfied with the time they were able to spend with patients (UK, 2\%; study average, 13\%) and was tied with Canada and Netherlands for the lowest 


\begin{tabular}{|c|c|c|c|c|c|c|c|c|c|c|c|c|c|}
\hline & Study average & OECD average & EU average & UK & AUS & CAN & FRA & GER & NLD & SWE & CHE & US & DEN \\
\hline \multicolumn{14}{|l|}{ Doctors } \\
\hline Practising, per 1000 population & 3.5 & 3.4 & 3.5 & 2.8 & 3.7 & 2.7 & 3.2 & 4.3 & 3.6 & 4.1 & 4.0 & 2.6 & 4.0 \\
\hline Change & 0.3 & 0.3 & 0.3 & 0.2 & 0.4 & 0.4 & 0.1 & 0.5 & 0.2 & 0.2 & 0.5 & 0.2 & 0.3 \\
\hline $\begin{array}{l}\text { Medical graduates, per } 1000 \\
\text { population }\end{array}$ & 12.5 & 13.0 & 14.6 & 12.9 & 15.5 & 7.7 & 9.5 & 12.0 & 13.5 & 11.5 & 11.2 & 7.8 & 21.5 \\
\hline Change & 1.7 & 2.7 & 2.9 & -0.7 & 3.4 & 0.5 & 3.7 & -0.1 & 2.3 & 1.1 & 0.8 & 1.1 & 5.0 \\
\hline \multicolumn{14}{|l|}{ Nurses } \\
\hline Practising, per 1000 population & 11.4 & 9.3 & 8.5 & 7.8 & 11.7 & 10.0 & 10.8 & 12.9 & 10.9 & 11.0 & 17.2 & 11.7 & 10 \\
\hline Change & 0.4 & 0.9 & 0.5 & -0.6 & 1.5 & 0.6 & 0.1 & 2.4 & 1.4 & 0.6 & -0.1 & 2.6 & 0.1 \\
\hline $\begin{array}{l}\text { Nursing graduates, per } 1000 \\
\text { population }\end{array}$ & 56 & 44.3 & 37.4 & 29.4 & 84.5 & 52.5 & 40.8 & 54.5 & 53.0 & 39.2 & 100.9 & 61.7 & 44 \\
\hline Change & 6.8 & 4.4 & 1.9 & 1.9 & 17 & 1.1 & 4.0 & 9.4 & 13.7 & -4.3 & 24.4 & -3.5 & 3.8 \\
\hline \multicolumn{14}{|l|}{ Workforce by type of care } \\
\hline $\begin{array}{l}\text { General practitioners, per } 1000 \\
\text { population }\end{array}$ & 1.1 & 1 & 1 & 0.8 & 1.6 & 1.3 & 1.4 & 1 & 1.6 & 0.7 & 1.1 & 0.3 & 0.8 \\
\hline Change & 0.1 & 0.1 & 0 & 0 & 0.1 & 0.2 & -0.2 & 0.1 & 0.4 & 0 & 0.5 & 0 & 0 \\
\hline Specialists, per 1000 population & 2.2 & 2.2 & 2.5 & 2.1 & 1.8 & 1.4 & 1.7 & 3.3 & 2 & 2.2 & 2.6 & 2.3 & 1.8 \\
\hline Change & 0.3 & 0.3 & 0.3 & 0.2 & 0.3 & 0.2 & 0.1 & 0.4 & 0.3 & 0.2 & 0.1 & 0.2 & 0.2 \\
\hline \multicolumn{14}{|l|}{ Foreign workforce } \\
\hline $\begin{array}{l}\text { Foreign trained doctors, \% of total } \\
\text { doctors) }\end{array}$ & 21.4 & 18.2 & 12.4 & 28.6 & 32.1 & 24.6 & 11.2 & 11.9 & 2.2 & 34.8 & 34.1 & 25 & 9.2 \\
\hline Change & 3 & 2.1 & 2.7 & -1.1 & -1 & 1.5 & 3.8 & 5.3 & -0.4 & 11.2 & 9.9 & 0.2 & 0.5 \\
\hline $\begin{array}{l}\text { Foreign trained nurses, \% of total } \\
\text { nurses }\end{array}$ & 9.3 & 6 & 3.2 & 15 & 18.4 & 8.1 & 2.9 & 7.9 & 0.5 & 3 & 25.9 & 6 & 1.8 \\
\hline Change & 1.8 & 0.7 & 0.2 & 1.6 & 1.2 & 0.9 & 0.4 & 1.7 & -0.6 & 0.4 & 11.2 & & -0.2 \\
\hline \multicolumn{14}{|l|}{ Staff satisfaction } \\
\hline $\begin{array}{l}\text { Physicians dissatisfied with } \\
\text { income, \% }\end{array}$ & 32 & NA & NA & 20 & 25 & 20 & 63 & 33 & 20 & 28 & 42 & 32 & - \\
\hline $\begin{array}{l}\text { Physicians dissatisfied with time } \\
\text { with patients, \% }\end{array}$ & 13 & NA & NA & 2 & 10 & 23 & 8 & 23 & 12 & 22 & 4 & 16 & - \\
\hline \multicolumn{14}{|l|}{ Beds } \\
\hline Total, per 1000 population & 4 & 4.7 & 4.8 & 2.5 & 3.8 & 2.5 & 6 & 8 & 3.3 & 2.2 & 4.5 & 2.8 & 2.6 \\
\hline Change & -0.5 & -0.3 & -0.5 & -0.4 & 0.1 & -0.3 & -0.5 & -0.3 & -0.9 & -0.5 & -0.4 & -0.3 & -0.9 \\
\hline $\begin{array}{l}\text { Mental health, per } 1000 \text { popu- } \\
\text { lation }\end{array}$ & 0.7 & 0.7 & 0.7 & 0.4 & 0.4 & 0.3 & 0.8 & 1.3 & 0.9 & 0.4 & 0.9 & 0.2 & 0.5 \\
\hline Change & -0.1 & -0.1 & -0.1 & -0.2 & 0.03 & -0.02 & -0.04 & 0.1 & -0.4 & -0.05 & -0.04 & -0.04 & -0.1 \\
\hline
\end{tabular}

percentage of physicians who were dissatisfied with their income (UK, 20\%; study average, 32\%). The UK had fewer total hospital beds per population than the average of all comparator groups (UK, 2.5; study average, 4; OECD, 4.7; EU, 4.8 beds/1000 population) (table 3). The number of beds in the UK decreased at a rate similar to the averages. The trends were similar for the numbers of beds for mental health services. Finally, remuneration of specialists and nurses in the UK was slightly below the average of the comparator countries (UK specialists, \$171987; study average specialists, \$182 657; UK nurses, \$49725; study average nurses, \$57946), but remuneration of general practitioners was similar to the mean of the group (UK, \$134671; study average, \$133 721) (supplementary figure C).

\section{Utilisation}

The UK had slightly fewer total consultations with doctors per capita compared with other comparator countries (UK, 5; study average, 5.7; OECD, 6.4; EU, 6.8 visits/person/year) and lower rates of all cause hospital discharges (UK, 12354; study average, 14919; OECD, 15 235; EU, 16218 discharges/100 000 population), which were also decreasing at a faster rate than the average (table 4). Primary care physicians in the UK reported spending the least amount of time with patients, with $0 \%$ spending 25 or more minutes with patients (study average, 15\%), 8\% reporting spending 15-25 minutes (study average, 45\%), and 92\% reporting spending less than 15 minutes with their patients (study average, 38\%). The rate of influenza immunisation among the population over age 65 was higher in the UK than in all comparator groups (UK, 72.6\%; study average, 54.1\%; OECD 43.2\%; EU $37.2 \%$ ) with the exception of Australia (74.6\%). Rates of breast cancer screening for women aged 50-69 and cervical cancer screening for women aged 20-69 were higher in the UK than the average for the comparator countries (breast: UK, 75.1\%; study average, 66.5\%; OECD, 61.5\%; EU 63.9\%; cervical: UK, 75.4\%; study average, 71\%, OECD, 63.6\%; EU, 64.9\%). However, both UK screening rates decreased at faster rates than the study average (table 4). Average length of hospital stay in the UK was 6.8 days, which was very close to the study average of 6.7 days and lower than the OECD average (7.3 days) and the EU average (7.4 days). Length of hospital stay for childbirth was 2.5 days in the UK, which was lower than the study average (3.2 days), the OECD average (3.5 days), and the EU average (3.6 days). 

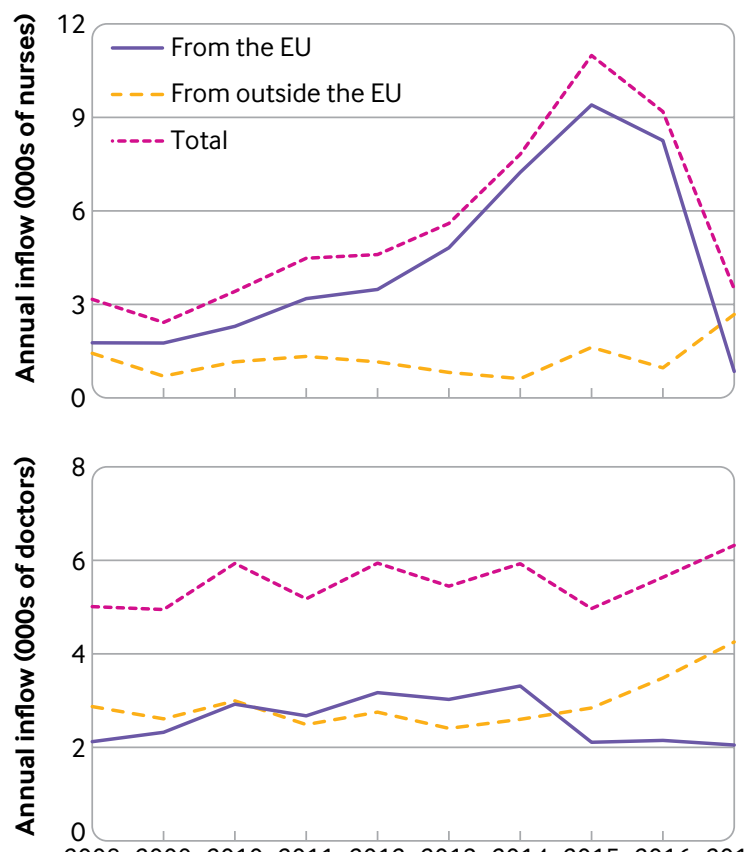

2008200920102011201220132014201520162017

Year

Fig 2 | Annual inflow of foreign trained workforce in UK. Top: Annual inflow of foreign trained nurses into UK. Bottom: Annual inflow of foreign trained doctors into UK. All data are presented as foreign trained workforce from European Union (EU) nations, nonEU nations, and total

\section{Access to care}

Waiting times across the UK were for the most part comparable to the average of the 10 countries, although considerable variation existed across the group. Sixty five per cent of UK patients reported seeing the doctor or nurse the next day when they last needed care, compared with an average of $67 \%$ across the countries (table 5). Twenty four per cent reported waiting six days or more for an appointment, compared with an average of $20 \%$ across the countries. UK waiting times were slightly longer for specialist care, with $19 \%$ reporting waiting two months or longer, compared with a group average of $12 \%$, but fewer patients reported visiting the emergency department for a condition that could have been treated by a regular doctor (UK, 7\%; study average, 9\%). The UK had the lowest rates for each category pertaining to unmet need, which included the percentage of adults having any cost related access problem (UK, 7\%; study average 15\%), skipping a medical test, treatment, or follow-up owing to cost (UK, 3\%; study average 8\%), and skipping prescribed drugs owing to costs (UK, $2 \%$; study average, $8 \%$ ). However, the proportion of adults skipping prescribed drugs owing to costs has risen since 2010 in the UK, despite decreasing in other countries.

\section{Quality of care}

We examined various aspects of quality of care across the 10 countries, including indicators related to patients' and providers' experience and health service outcomes such as mortality and adverse events. The UK population had a similar perception of how well the NHS functions compared with other populations' views about their healthcare systems. Specifically, $44 \%$ of UK adults reported that they thought the healthcare system worked well (compared with the study average of 45\%), although this had declined by 19 percentage points since 2010 (table 6). Other national surveys of the UK population, such as the British Attitudes Survey, show

\begin{tabular}{|c|c|c|c|c|c|c|c|c|c|c|c|c|c|}
\hline & Study average & OECD average & EU average & UK & AUS & CAN & FRA & GER & NLD & SWE & CHE & US & DEN \\
\hline \multicolumn{14}{|l|}{ Doctor visits } \\
\hline $\begin{array}{l}\text { Total No of consultations, per } \\
\text { capita }\end{array}$ & 5.7 & 6.4 & 6.8 & 5 & 6.6 & 7 & 6.7 & 9.9 & 6.6 & 2.9 & 3.9 & 4 & 4.6 \\
\hline \multicolumn{14}{|l|}{ Hospital discharges } \\
\hline $\begin{array}{l}\text { All causes, per } 100000 \\
\text { population }\end{array}$ & 14919 & 15235 & 16218 & 12354 & 17996 & 8,461 & 18609 & 25478 & 9247 & 12937 & 17069 & 12549 & 14492 \\
\hline Change & -378 & -457 & -933 & -856 & 1105 & 185 & 1736 & 1485 & -2690 & -3314 & 157 & -542 & -1584 \\
\hline \multicolumn{14}{|c|}{ Time spent with patient during routine visit } \\
\hline$<15$ minutes, $\%$ of GPs & 38 & NA & NA & 92 & 28 & 30 & 5 & 80 & 85 & 2 & 8 & 16 & - \\
\hline 15 to $<25$ minutes, $\%$ of GPs & 45 & NA & NA & 8 & 66 & 53 & 72 & 16 & 14 & 49 & 68 & 63 & - \\
\hline$\geq 25$ minutes, $\%$ of GPs & 15 & NA & NA & 0 & 5 & 16 & 21 & 2 & 0 & 48 & 24 & 20 & - \\
\hline \multicolumn{14}{|l|}{ Immunisation } \\
\hline $65+$ receiving flu vaccine, $\%$ & 54.1 & 43.2 & 37.2 & 72.6 & 74.6 & 61.1 & 49.7 & 34.8 & 64 & 49.4 & 46 & 67.5 & 40.8 \\
\hline Change & -6.4 & -1.5 & -2.5 & -0.2 & - & 1.7 & -6.5 & -21.3 & -10 & -5.8 & - & 3.6 & -4.8 \\
\hline \multicolumn{14}{|l|}{ Cancer screening } \\
\hline Breast, \% of women $50-69$ & 66.5 & 61.5 & 63.9 & 75.1 & 55.1 & 54 & 49.7 & 51 & 79.3 & 90.4 & 49 & 79.5 & 82.1 \\
\hline Change & 2.2 & 3.3 & 4.3 & -1.7 & -0.8 & 0.2 & -3 & -2.7 & -2.2 & 0 & - & -0.9 & 4.7 \\
\hline Cervical, \% of women $20-69$ & 71 & 63.6 & 64.9 & 75.4 & 55.4 & 61 & 75.4 & 80.4 & 56.9 & 82.9 & 75.5 & 83.3 & 63.5 \\
\hline Change & -0.1 & 3.7 & 6 & -3.5 & -2.4 & -3 & 4.3 & 1.7 & -8.6 & 2.8 & 1.9 & -1.7 & -1.4 \\
\hline \multicolumn{14}{|l|}{ Length of stay } \\
\hline $\begin{array}{l}\text { Total (all causes, inpatient), } \\
\text { days }\end{array}$ & 6.7 & 7.3 & 7.4 & 6.8 & 5.6 & 8 & 8.8 & 8.9 & 4.5 & 5.6 & 8.2 & 4.8 & 5.4 \\
\hline Change & -0.1 & -0.1 & -0.2 & -0.6 & -0.2 & 0.3 & -3.1 & -0.6 & -1.1 & -0.4 & -0.8 & -0.1 & -0.5 \\
\hline Childbirth, days & 3.2 & 3.5 & 3.6 & 2.5 & 3.2 & 2.3 & 4.3 & 3.8 & 2.7 & 2.6 & 4.1 & 2.8 & 2.9 \\
\hline Change & -0.3 & -0.1 & -0.3 & 0.1 & -0.2 & -0.1 & -0.4 & -0.7 & -0.5 & -0.1 & -0.7 & 0 & -0.4 \\
\hline
\end{tabular}




\begin{tabular}{|c|c|c|c|c|c|c|c|c|c|c|c|c|}
\hline & Study average & OECD average & EU average & UK & AUS & CAN & FRA & GER & NLD & SWE & CHE & US \\
\hline \multicolumn{13}{|l|}{ Waiting times } \\
\hline Saw doctor or nurse on next day last time needed care, \% & 67 & NA & NA & 65 & 71 & 45 & 83 & 81 & 76 & 53 & 69 & 57 \\
\hline Waited $\geq 6$ days appointment, $\%$ & 20 & NA & NA & 24 & 9 & 29 & 22 & 34 & 8 & 28 & 12 & 18 \\
\hline Waited $\geq 2$ months for specialist appointment, \% & 12 & NA & NA & 19 & 13 & 30 & 4 & 3 & 7 & 19 & 9 & 6 \\
\hline $\begin{array}{l}\text { Visited ED for condition that could have been treated by } \\
\text { regular doctor, \% }\end{array}$ & 9 & NA & NA & 7 & 6 & 17 & 7 & 5 & 6 & 12 & 9 & 16 \\
\hline Change & 2 & NA & NA & 3 & -1 & 2 & 3 & 2 & 0 & 2 & 1 & 3 \\
\hline \multicolumn{13}{|l|}{ Unmet need } \\
\hline Any cost related access problem in previous year, $\%$ of adults & 15 & NA & NA & 7 & 14 & 16 & 17 & 7 & 8 & 8 & 22 & 33 \\
\hline Change & 7 & NA & NA & 2 & 6 & 7 & 14 & 0 & 2 & 4 & 16 & 14 \\
\hline $\begin{array}{l}\text { Medical tests, treatment, or follow-up skipped owing to } \\
\text { costs, \% of adults }\end{array}$ & 8 & NA & NA & 3 & 4 & 6 & 10 & 4 & 9 & 4 & 13 & 20 \\
\hline Change & -0.2 & NA & NA & -0.3 & -10.3 & 0.3 & 3.3 & -5.1 & 6.4 & -0.9 & 7.8 & -3.2 \\
\hline Prescribed drugs skipped owing to costs, $\%$ of adults & 8 & NA & NA & 2 & 8 & 11 & 8 & 3 & 7 & 7 & 12 & 18 \\
\hline Change & -0.1 & NA & NA & 0.4 & -4.8 & 0.3 & 0.5 & -2.9 & 3.3 & -1.7 & 7.5 & -3.9 \\
\hline
\end{tabular}

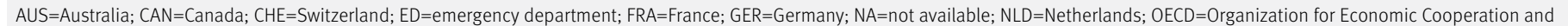

Development; $\mathrm{SWE}=$ Sweden.

Values are 2017 or nearest year. Change represents difference from 2010 (or nearest year) values.

a growing consensus among the general population that the NHS faces a major or severe funding problem (86\% of respondents in 2017, up from $14 \%$ in 2014). ${ }^{13}$ General practitioners' views of the health system were not as favourable as in comparator countries, with only $22 \%$ of primary care physicians reporting that they thought the healthcare system worked well (compared with the study average of 33\%). Moreover, the number of primary care physicians reporting that the system worked well in 2015 had decreased by 24 percentage points from 2012, compared with a mean change of 8 percentage points across all 10 countries (table 6).

A smaller proportion of the UK population reported experiencing a problem with care coordination and a gap in hospital discharge planning than in all other study countries (UK, $19 \%$ and 28\%, respectively;

Table 6 | Quality of care in UK and comparator countries, 2017 and change from 2010

Study average OECD average EU average UK AUS CAN FRA GER NLD SWE CHE US DEN

Population satisfaction

\begin{tabular}{llllllllllllllll}
\hline Think healthcare system works well, \% of adults & 45 & NA & NA & 44 & 44 & 35 & 54 & 60 & 43 & 31 & 58 & 19 & -
\end{tabular}

Change

GP experience

Think healthcare system works well, $\%$ of physicians 33

Change

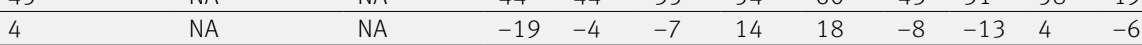

Care continuity

Experienced problem with care coordination, \%

$$
\text { Change }
$$

Experienced gap in hospital discharge planning, \% 39

Change

33

$\begin{array}{llll}N A & N A & 22 & 48\end{array}$

$-8-N A$

NA

$-24$

$48 \quad 36$

$\begin{array}{ll}36 & 2 \\ -4 & -8\end{array}$

Avoidable admissions

Diabetes, per 100000 population aged $\geq 15$ Change

COPD, per 100000 population aged $\geq 15$

27
0.8
39

NA
NA
NA
NA

NA

$-10-N A$

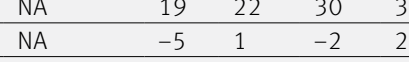

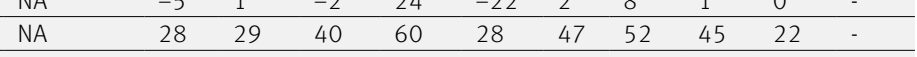

\begin{tabular}{|c|c|c|c|c|c|c|c|c|c|c|c|c|c|}
\hline Change & 0 & -4 & -7 & -15 & -10 & -9 & 29 & 38 & 13 & -15 & 16 & - & -9 \\
\hline \multicolumn{14}{|l|}{ Mortality } \\
\hline AMI, rate/100 patients & 5.5 & 7.6 & 7.1 & 7.1 & 4.0 & 5.1 & 5.6 & 7.7 & 5.4 & 4.2 & 5.1 & 6.5 & 4.0 \\
\hline Change & -1.0 & -1.0 & -1.2 & -1.1 & -1.1 & -2.4 & -0.6 & -1.9 & -1.8 & -0.6 & -0.8 & 1.0 & -0.9 \\
\hline Ischaemic stroke, rate/100 patients & 6.6 & 8.4 & 8.9 & 9.6 & 6.7 & 8.5 & 7.1 & 6.2 & 7.3 & 6.1 & 5.4 & 4.1 & 4.6 \\
\hline Change & -1.6 & -0.9 & -0.9 & -2.2 & -3.4 & -2.8 & -1.4 & -0.7 & -1.1 & -0.6 & -1.6 & -0.2 & -2.0 \\
\hline \multicolumn{14}{|l|}{ Patient safety } \\
\hline $\begin{array}{l}\text { Postoperative pulmonary embolism after hip or knee } \\
\text { replacement, per } 100000 \text { discharges }\end{array}$ & 330 & 286 & 246 & 316 & 549 & 657 & 267 & 341 & - & 166 & 339 & 294 & - \\
\hline Change & 19 & -60 & -32 & -7 & -5 & 31 & -44 & 58 & - & -18 & 74 & - & - \\
\hline $\begin{array}{l}\text { Postoperative DVT after hip or knee replacement, per } \\
100000 \text { discharges }\end{array}$ & 489 & 347 & 351 & 202 & 1113 & 311 & 1328 & 419 & - & 90 & 237 & 209 & - \\
\hline Change & -215 & -119 & -115 & -39 & -58 & -28 & -809 & -203 & - & -44 & -45 & - & - \\
\hline $\begin{array}{l}\text { Postoperative sepsis after abdominal surgery, per } \\
100000 \text { discharges }\end{array}$ & 2058 & 1821 & 1949 & 2454 & 2658 & 1365 & - & 1862 & - & 1352 & 2371 & 2129 & 2269 \\
\hline Change & 618 & 236 & 253 & 850 & 467 & 131 & - & 317 & - & 205 & 1268 & - & 1017 \\
\hline Healthcare associated infections, \% prevalence & 6.6 & NA & 5.5 & 5.2 & & & 4.9 & 5 & 7.4 & 7.3 & & & 9.8 \\
\hline
\end{tabular}

$\mathrm{AMI}=$ acute myocardial infarction; $\mathrm{AUS}=$ Australia; $\mathrm{CAN}=\mathrm{Canada}$; $\mathrm{CHE}=$ Switzerland; $\mathrm{COPD}=$ chronic obstructive pulmonary disease; $\mathrm{DEN}=\mathrm{Denmark}$; DVT=deep venous thrombosis; $\mathrm{FRA=France;}$ $\mathrm{GER}=$ Germany; $\mathrm{GP}=$ general practitioner; $\mathrm{NA}=$ not available; NLD=Netherlands; $\mathrm{OECD}=$ Organization for Economic Cooperation and Development; $S W E=S w e d e n$.

Values are 2017 or nearest year. Change represents difference from 2010 (or nearest year) values. 
study averages, 27\% and 39\%, respectively) (table 6). Although the UK had fewer avoidable admissions to hospitals for diabetes among the adult population (UK, 73; study average, 122; OECD, 138; EU, 135/100000 population), it had more avoidable admissions for chronic obstructive pulmonary disease (UK, 232; study average, 204; OECD, 194; EU, 194/100000 population). Thirty day mortality for acute myocardial infarction in the UK was among the highest relative to comparator countries (7.1\%; study average, 5.5\%), after Germany (7.7\%), although it was comparable to the average OECD and EU rates $(7.6 \%$ and $7.1 \%$, respectively). The UK also had the highest three day mortality for ischaemic stroke (UK, 9.6\%; study average, 6.6\%; OECD, 8.4\%; EU, 8.9\%). However, both of these mortality rates declined to a greater extent from 2010 values in the UK compared with the group average.

The UK performed slightly better than the study average for measures of patient safety, including postoperative pulmonary embolism after hip or knee replacement (UK, 316; study average, 330; OECD, 286; EU, 246/100000 discharges), postoperative deep venous thrombosis (UK, 202; study average, 489; OECD, 347; EU, 351/10000 discharges), and the prevalence of healthcare associated infections (UK, 5.2\%; study average, 6.6\%). However, rates were higher for postoperative sepsis after abdominal surgery (UK, 2454; study average, 2058; OECD, 1821; EU, 1949/100 000 discharges) (table 6).

\section{Population health}

Life expectancy at birth in the UK was just below the average of the comparator countries (UK, 81.3 years; study average, 81.7 years) (fig 3). Life expectancy in the UK has been below the average over the past 20 years, although the gap narrowed over the period 2008-13 to a low of 0.3 years (fig 2). Owing to recent increases in mortality in the UK in 2014-15, this gap once again increased, although it seems to be closing again as life expectancy improved in 2016 and 2017. As a result of large improvements in the UK in recent years, smoking rates in 2017 were below average compared with comparator countries, the OECD, and the EU (UK, 16.1\%; study average, 16.5\%; OECD,
18.4\%; EU, 20.1\%). The rate of alcohol consumption was about average, and the prevalence of overweight and obesity was above average relative to comparators (alcohol consumption: UK; 9.7; study average, 9.3; OECD, 8.9; EU, 10 L per capita; overweight and obesity: UK, 64\%; study average, 54.7\%; OECD, 55.1\%; EU, $54.6 \%$ ) (table 7).

Among the European countries where preventable deaths and treatable deaths are measured, the UK had greater than average rates of preventable deaths compared with the study average (UK, 154; study average, 139 deaths/100000 population), and the highest rates of amenable deaths (UK, 90; study average, 72 deaths/100 000 population). However, the UK performed similarly to the average of the EU (161 and 93 deaths/100000 population for preventable and treatable causes, respectively) (table 7). Improvements in each of these measures over the previous five years in the UK was below the average improvement of the group. Maternal mortality in the UK was 7.8 deaths/100000 live births, which was greater than the mean of the comparators (5.5 deaths/100000 births) and above the OECD and EU averages (7.0 and 6.4 deaths/100000 births, respectively); this represents an increase from 2010 values by 0.8 deaths (table 7 ). The UK had similar rates of infant mortality to other countries (UK, 3.9; study average, 3.8; OECD, 3.7; EU, 3.2 deaths/1000 live births), and they are decreasing at a similar rate to the average (UK, -0.3 deaths; study average, -0.2 deaths). The only countries with higher rates of infant deaths were Canada (4.5 deaths/1000 live births) and the US (5.8 deaths/1000 live births). The UK had the lowest survival rates for breast cancer (UK, 85.6\%; study average, 87.4\%) and colon cancer (UK, 60\%; study average, 64.8\%), and the second lowest for rectal cancer (UK, 62.5\%; study average, $66.6 \%$ ) and cervical cancer (UK, 63.8\%; study average $66.6 \%$ ). Prevalence of diabetes was lower in the UK than the average of the group (UK, $4.3 \%$; study average, $6.3 \%$; OECD, 6.5\%; EU, 6.1\%), but the prevalence of depression and dementia were about average (depression: UK, 2.9\%; study average, 2.8\%; OECD, 2.6\%; EU, 2.6\%; dementia: UK; 17; study average, 16.4; OECD, 14.8; EU, 15.8 per 1000 population).

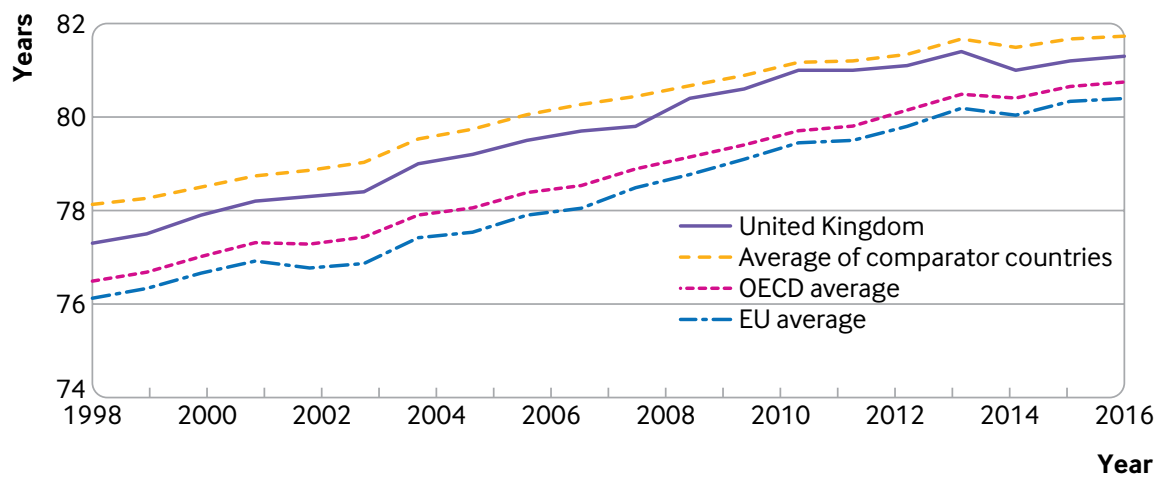

Fig 3 | Total population life expectancy at birth in UK, average of comparator countries, average of Organization for Economic Cooperation and Development (OECD) member countries, and average of European Union (EU) member countries 


\begin{tabular}{|c|c|c|c|c|c|c|c|c|c|c|c|c|c|}
\hline & Study average & OECD average & EU average & UK & AUS & CAN & FRA & GER & NLD & SWE & CHE & US & DEN \\
\hline \multicolumn{14}{|l|}{ Non-medical determinants of health } \\
\hline Smoking, $\%$ of adults $\geq 15$ & 16.5 & 18.4 & 20.1 & 16.1 & 12.4 & 14 & 22.4 & 20.9 & 19 & 11.2 & 20.4 & 11.4 & 17 \\
\hline Change & -8.3 & -7.3 & -6.7 & -10.9 & -7.2 & -8.4 & -4.6 & -3.8 & -13 & -7.7 & -6 & -7.7 & -13.5 \\
\hline Alcohol consumption, L per capita $\geq 15$ & 9.3 & 8.9 & 10 & 9.7 & 9.4 & 8.1 & 11.7 & 10.9 & 8.3 & 7.1 & 9.2 & 8.9 & 9.1 \\
\hline Change & -0.5 & -0.4 & -0.5 & -0.4 & -0.9 & -0.3 & -0.6 & -0.5 & -0.8 & -0.2 & -0.8 & 0.3 & -1.2 \\
\hline $\begin{array}{l}\text { Overweight including obesity, \% of total popu- } \\
\text { lation }\end{array}$ & 54.7 & 55.1 & 54.6 & 64 & 65 & 60 & 46 & 53 & 47 & 48 & 42 & 71 & 51 \\
\hline Change & 1.6 & 2.7 & 1.6 & -2 & -2 & 0.5 & 3.2 & 0.3 & -1 & 2 & 1 & 2 & 4.3 \\
\hline \multicolumn{14}{|l|}{ Avoidable mortality } \\
\hline Preventable deaths, per 100000 population & 139 & NA & 161 & 154 & - & - & 133 & 158 & 134 & 121 & 111 & - & 161 \\
\hline Change & -11 & NA & -14 & -5 & - & - & -14 & -6 & -7 & -6 & -12 & - & -23 \\
\hline Treatable deaths, per 100000 population & 72 & NA & 93 & 90 & - & - & 62 & 87 & 69 & 68 & 53 & - & 76 \\
\hline Change & -9 & NA & -10 & -4 & - & - & -5 & -8 & -10 & -10 & -10 & - & -15 \\
\hline \multicolumn{14}{|l|}{ Maternal/infant mortality } \\
\hline Maternal mortality, per 100000 births & 5.5 & 7.0 & 6.4 & 7.8 & 1.6 & 6.6 & 8.7 & 2.9 & 1.8 & 3.5 & 4.6 & 17.2 & 1.6 \\
\hline Change & -0.5 & -2.1 & -0.6 & 0.8 & -2.7 & 0.2 & -1.5 & -2.3 & -0.4 & 0.9 & 0.9 & 0.5 & -3.5 \\
\hline Infant mortality, per 1000 live births & 3.8 & 3.7 & 3.2 & 3.9 & 3.3 & 4.5 & 3.9 & 3.3 & 3.6 & 2.4 & 3.5 & 5.8 & 3.8 \\
\hline Change & -0.2 & -0.7 & -0.5 & -0.3 & -0.8 & -0.5 & 0.4 & -0.1 & -0.2 & -0.1 & -0.3 & -0.3 & 0.4 \\
\hline \multicolumn{14}{|l|}{ Cancer survival } \\
\hline Breast cancer survival, 5 year net $\%$ & 87.4 & 84.7 & 83.2 & 85.6 & 89.5 & 88.2 & 86.7 & 86 & 86.6 & 88.8 & 86.2 & 90.2 & 86.1 \\
\hline Change & 0.7 & 1.1 & 1.1 & 1.8 & 1.0 & 0.7 & -0.5 & 0.4 & 0.8 & 0.9 & -0.2 & 0.4 & 2.1 \\
\hline Cervical cancer survival, 5 year net \% & 66.6 & 65.7 & 63.6 & 63.8 & 66.4 & 66.6 & 65 & 65.2 & 67.5 & 68.3 & 71.4 & 62.6 & 69.5 \\
\hline Change & 1.0 & 0.4 & 0.6 & 1.9 & -1.1 & -0.3 & 2.9 & -0.5 & 2.0 & 0.6 & 2.0 & -0.4 & 2.8 \\
\hline Colon cancer survival, 5 year net $\%$ & 64.8 & 62.4 & 60.5 & 60 & 70.6 & 66.9 & 63.7 & 64.8 & 63 & 64.9 & 67.2 & 64.9 & 61.6 \\
\hline Change & 1.7 & 1.9 & 2.2 & 3.5 & 2.5 & 1.3 & 0.1 & -0.1 & 2.1 & 0.6 & 2.1 & -0.6 & 5.1 \\
\hline Rectal cancer survival, 5 year net \% & 66.6 & 65.7 & 63.6 & 62.5 & 71 & 66.6 & 60.9 & 62.2 & 65.3 & 64.7 & 67.3 & 64.1 & 64.8 \\
\hline Change & 1.0 & 0.4 & 0.6 & 3.8 & 2.4 & 1.2 & 0.2 & 0 & 2.2 & 1.7 & 1.6 & -0.4 & 5 \\
\hline \multicolumn{14}{|l|}{ Prevalence of chronic conditions } \\
\hline Depression prevalence, \% & 2.8 & 2.6 & 2.6 & 2.9 & 3.3 & 2.2 & 3.3 & 2.6 & 2.6 & 3.3 & 2.5 & 3.2 & 2 \\
\hline Change & -0.1 & 0 & 0 & 0 & -0.3 & 0 & -0.1 & 0.1 & 0 & -0.1 & -0.1 & -0.1 & 0 \\
\hline Diabetes prevalence, $\%$ ages 20-79 & 6.3 & 6.5 & 6.1 & 4.3 & 5.1 & 7.4 & 4.8 & 8.3 & 5.3 & 7.6 & 5.6 & 10.8 & 6.4 \\
\hline Dementia prevalence, per 1000 population & 16.4 & 14.8 & 15.8 & 17 & 14 & 13 & 20 & 20 & 16 & 18 & 17 & 12 & 16 \\
\hline
\end{tabular}

\section{Discussion}

In this study, based on aggregated data from recent years, the UK was consistently the country that spent the least on healthcare per capita compared with nine other high performing health systems. When compared with the 35 member states of the OECD and the 28 member states of the EU, UK healthcare spending was about average. Relative to other countries, the NHS has lower amounts of labour, which have been decreasing at a faster rate, particularly after 2015 , when large decreases in the annual inflow of EU trained healthcare professionals have been seen. Despite spending less than comparators, the UK NHS manages to achieve universal population coverage with perceptions of access that were among the highest of all countries examined, while utilisation of care was lower than the average of comparators. However, health service outcomes and measures of population health status are among the lowest in the group and have worsened over the past decade. Taken together, these results suggest that, if the UK NHS wants to achieve comparable health outcomes to other high income countries, or even improve outcomes, it needs to invest more on factors that can reverse the decline of health service outcomes and health status overall. In particular, our study suggests that the NHS should look towards improving staffing ratios, long term care provision, and social spending, which are lower than comparator countries and have been declining in recent years.

\section{Contribution to previous studies and common narratives on NHS performance}

Our findings shed light on some of the most common narratives about the current challenges facing the NHS by taking a comparative perspective to put national numbers into context. A few key findings warrant highlighting. Although the UK has comparable numbers of people over the age of 65 , it spends less of its already low total healthcare expenditure on long term care. Furthermore, a much greater proportion of long term care expenditure in the UK comes from private sources than in other healthcare systems. Finally, the UK seems to have much higher rates of informal care than the comparator countries, with high proportions of the workforce reporting that they are out of work or in part time employment because they are providing care. ${ }^{14}$ In 2017 long term care made up the second largest category of private household spending in the UK, accounting for $36 \%$ of out of pocket spending, after spending on medical goods which accounted for $38 \% .{ }^{15}$ In both healthcare and areas of social spending, expenditures coming from the 
public purse are declining and greater amounts are coming from private sources.

The role of migrants in the NHS has been a considerable focus in recent years, with regards to increasing demand pressures on the NHS from migrants as healthcare users, but also in terms of their role as providers of care. We found that both in absolute magnitude and as a proportion of the population, migrants in the UK make up less of the population than the average of comparator countries. Unless migrants coming to the UK are somehow dramatically sicker than those going to other similar countries, they are unlikely to be putting disproportionately greater pressure on healthcare demand in the UK than elsewhere. When it comes to the healthcare workforce, we found that the UK had among the highest proportion of foreign trained doctors and nurses. Despite this, the numbers of all types of healthcare professionals reported (general practitioners, specialists, and nurses) were some of the lowest of all countries studied, and the numbers are declining. As the migration of healthcare professionals has decreased since 2015, as evidenced by an $87 \%$ drop in new nurses coming from the EU to work in the UK from $2016-17$ to $2017-18,{ }^{16}$ the existing staffing challenges facing the NHS will clearly be further exacerbated. Policy makers should consider how recent changes to nursing bursaries, the weakened pound, and uncertainty about the status of immigrant workers in the light of the Brexit referendum result have influenced these numbers and how to respond to these challenges in the future.

Other aspects of structural capacity in the UK NHS compared with other health systems suggest problems with sustainability of care. The numbers of beds in the UK are at the lower end of the distribution of comparator countries and well below the average of the OECD and the EU. Although pay for doctors has been a major focus in the media, we found that relative to other countries the remuneration of doctors was about average, both in terms of nominal pay and as a ratio to the national wage. Moreover, physicians in the UK were less likely to report being dissatisfied with their incomes than were those in many comparator countries. Pay for nurses in the UK, however, was lower than the average across countries in both nominal and relative terms.

With regards to access to care, we found that the UK had average waiting times for specialist and primary care. Although the total number of consultations and hospital admissions in the UK was slightly below the average, it was not the lowest, despite having some of the lowest staffing levels. UK primary care physicians reported spending less time with their patients than did all other comparators. Ratings of patient experience and population satisfaction were similar to those in other countries, but have declined by a large amount in recent years, and a lower number of general practitioners in the UK than in other countries reported experiencing problems with continuity of care for their patients.
One of the biggest ongoing debates about the NHS has to do with the extent to which services are able to cope with government cuts to long term care funding and sluggish NHS funding. With the exception of patient safety measures, for which the UK performed slightly better than average on most measures, we found that most health service outcomes were below average and, in many cases, were the lowest of the group. Mortality rates for acute myocardial infarction and ischaemic stroke were the second highest and highest respectively. Compared with the wider OECD and EU averages, they were average at best. Cancer survival rates were the lowest of the comparator countries for breast and colon cancer, with cervical and rectal cancer survival being the second lowest. Maternal mortality in the UK was higher than for all comparators except the US and Germany, and is increasing. The numbers of preventable and treatable deaths in the population were the third highest and highest respectively. These findings may represent the difficulty of delivering the full set of services in a constrained setting with fewer providers and beds: the quality of the service may be beginning to suffer.

This analysis extends a body of work that has examined recent funding cuts in the NHS and their effect on performance. Many local reports in the academic literature and the media have noted the effect that funding cuts have had on emergency waiting times, hospital emergency alerts over winter months, and delayed discharge. ${ }^{13}$ This work shows that relative to other countries, the UK is also lagging behind with regards to many health service outcomes and population health measures, confirming other findings such as the poor comparative cancer outcomes highlighted in recent reports, despite large improvements in recent years. ${ }^{4}$

\section{Limitations of study}

This study has several limitations. Firstly, the data presented in this paper are purely descriptive; we did no statistical analyses to determine whether the UK's performance was statistically different from that of the comparator countries. In some cases, differences between countries and over time were small and may have been influenced by the comparability of patients and supply-side factors across countries and over time. Secondly, the data available to provide a true "apples with apples" comparison were limited. To ensure the validity of the data presented, we selected indicators from sources that have well established processes for validating national data with country representatives. Thirdly, our paper presents aggregate data for all of the UK, which does not take into account the large differences that exist in the NHS across the four constituent countries in the UK-namely, England, Scotland, Wales, and Northern Ireland. This was largely to do with the difficulty in finding comparable data across these countries. Finally, our main comparison is with nine other countries, all of which spend more on healthcare than the UK does. Perhaps our relative assessment of the UK would be more favourable had 
a different set of countries been chosen, representing a group that spends a closer proportion of GDP on their healthcare systems to the UK, such as Portugal, Spain, and Italy. We chose to focus the comparison on a group of countries that we believe the UK tends to liken itself to, ${ }^{717}$ almost all part of the G12 and very high income. However, to show the sensitivity of the interpretation to the selection of comparator countries, we also show the comparison of UK performance with the average performance of all OECD countries and all EU countries.

\section{Conclusion and policy implications}

We examined 79 health systems metrics in the UK and nine comparable countries and found that the UK had lower spending and slower growth in expenditure than comparators. Several factors contribute to the relatively low expenditure in the UK, including lower levels of doctor and nurse staffing, lower rates of utilisation, and less provision of long term care than comparators. Despite already low levels of labour, the UK is making do with fewer doctors and nurses, a challenge that is likely to be exacerbated in the context of Brexit. Although access to care compared favourably to other countries, utilisation was lower than average and quality seems to be slipping. Health service outcomes, as well as heath status, are suboptimal. This work suggests that although the NHS has done a remarkable job in managing the constrained funding environment, the broader challenges are such that if the UK wants an NHS that remains high performing and a nation with good health outcomes, it will almost certainly need to spend more on healthcare staffing, long term care, and other social services, which lag behind comparators.

Contributors: IP led the design of the study, guided the data collection and creation of tables and figures, and drafted the manuscript. EM provided critical guidance on the project to make it as relevant to a UK audience as possible and contributed to the drafting of manuscript. AG contributed to data collection, table and figure creation, and drafting of the manuscript. LW participated in data collection and drafting of the manuscript. AKJ supervised the data collection and drafting of the manuscript. The corresponding author attests that all listed authors meet the criteria for authorship and that no others meeting the criteria have been omitted. All authors have read and approved the final draft. IP is the guarantor.

Funding: None.

Competing interests: All authors have completed the ICMJE uniform disclosure form at www.icmje.org/coi_disclosure.pdf (available on request from the corresponding author) and declare: no support from any organisation for the submitted work; no financial relationships with any organisations that might have an interest in the submitted work in the previous three years; no other relationships or activities that could appear to have influenced the submitted work.

Ethical approval: Not needed, as the study relied solely on secondary, aggregated data and involved no human participants. Transparency: The lead author (the manuscript's guarantor) affirms that this manuscript is an honest, accurate, and transparent account of the study being reported; that no important aspects of the study have been omitted; and that any discrepancies from the study as planned (and, if relevant, registered) have been explained. Data sharing: No additional data available.

This is an Open Access article distributed in accordance with the Creative Commons Attribution Non Commercial (CC BY-NC 4.0) license, which permits others to distribute, remix, adapt, build upon this work non-commercially, and license their derivative works on different terms, provided the original work is properly cited and the use is noncommercial. See: http://creativecommons.org/licenses/by-nc/4.0/.

1 Maguire D, Dunn P, McKenna H. How hospital activity in the NHS in England has changed over time. 2016. https://www.kingsfund.org. uk/publications/hospital-activity-funding-changes.

2 Luchinskaya D, Simpson P, Stoye G. UK Health and Social Care Spending. 2017. https://www.ifs.org.uk/uploads/publications/ budgets/gb2017/gb2017ch5.pdf.

3 Hazell B, Robson R. Pharmaceutical waste reduction in the NHS. 2015. https://www.england.nhs.uk/wp-content/uploads/2015/06/ pharmaceutical-waste-reduction.pdf.

4 Richards M, Thorlby R, Fisher R, Turton C. Unfinished business: An assessment of the national approach to improving cancer services in England 1995-2015. 2018. https://www.health.org.uk/sites/ default/files/upload/publications/2018/Unfinished-business-anassessment-of-the-national-approach-to-improving-cancer-servicesin-england-1995-2015.pdf.

5 Dixon J, Street A, Allwood D. Productivity in the NHS: why it matters and what to do next. BMJ 2018;363:k4301. doi:10.1136/bmj. k4301

6 Mossialos E, McGuire A, Anderson M, Pitchforth E, James A, Horton $\mathrm{R}$. The future of the NHS: no longer the envy of the world? Lancet 2018:391:1001-3. doi:10.1016/S0140-6736(18)30574-9

7 Schneider EC, Sarnak DO, Squires D, Shah A, Doty MM. Mirror, Mirror 2017: International Comparison Reflects Flaws and Opportunities for Better U.S. Health Care. 2017. https://www.commonwealthfund. org/publications/fund-reports/2017/jul/mirror-mirror-2017international-comparison-reflects-flaws-and.

8 Papanicolas I, Woskie LR, Jha AK. Health care spending in the United States and other high-income countries. JAMA 2018;319:1024-39. doi:10.1001/jama.2018.1150

9 Kanavos P, Mossialos E. International comparisons of health care expenditures: what we know and what we do not know. J Health Serv Res Policy 1999;4:122-6. doi:10.1177/135581969900400211

10 Murray CJL, Frenk J. A framework for assessing the performance of health systems. Bull World Health Organ 2000;78:717-31.

11 Appleby J. How does NHS spending compare with health spending internationally? 2016. https://www.kingsfund.org.uk/blog/2016/01/ how-does-nhs-spending-compare-health-spending-internationally.

12 Appleby J, Boyle S. Blair's billions: where will he find the money for the NHS?BMJ 2000;320:865-7. doi:10.1136/bmj.320.7238.865

13 Ham C. Theresa May's choice: give the NHS more money, or tell voters to expect worse care. 2017. https://www.telegraph.co.uk/ news/2017/01/13/theresa-mays-choice-give-nhs-money-tellvoters-expect-worse/.

14 Courtin E, Jemiai N, Mossialos E. Mapping support policies for informal carers across the European Union. Health Policy 2014;118:84-94. doi:10.1016/j.healthpol.2014.07.013

15 Office for National Statistics. Healthcare expenditure, UK Health Accounts: 2017. 2019. https://www.ons.gov.uk/ peoplepopulationandcommunity/healthandsocialcare/ healthcaresystem/bulletins/ukhealthaccounts/2017.

16 The Health Foundation. Large drop in the number of new nurses coming from the EU to work in the UK. 2018. https://www.health. org.uk/chart/chart-large-drop-in-the-number-of-new-nurses-comingfrom-the-eu-to-work-in-the-uk.

17 Dayan M, Ward D, Gardner T, Kelly E. How good is the NHS? 2018. http://allcatsrgrey.org.uk/wp/download/health_services/the-nhs-at70-how-good-is-the-nhs.pdf.

Technical appendix

Suplementary figures 